\section{Edyeasáa

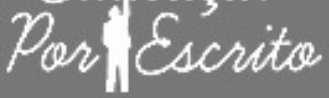

ARTIGO

\section{Editora}

Maria Inês Côrte Vitoria PUCRS, RS, Brasil

\section{Editora Colaboradora}

Pricila Kohls dos Santos PUCRS, RS, Brasil

\section{Equipe Editorial}

Carla Spagnolo

PUCRS, Brasil

Rosa Maria Rigo

PUCRS, Brasil

\title{
Contribuições do PIBID para a prática pedagógica de professores em início de carreira
}

\author{
PIBID contributions to the pedagogical practice of teachers \\ at the beginning of career
}

\section{Ricardo Luiz de Bittencourt ${ }^{1}$} Giana Medeiros ${ }^{2}$

\section{RESUMO}

O Estado brasileiro vem desde a metade da década de 1990 implementando políticas que têm a pretensão de regular a formação de professores. Uma das iniciativas do governo federal que diz respeito à formação de professores é o Programa Institucional de Bolsas de Iniciação à Docência - PIBID. O objetivo deste artigo é analisar as contribuições desse programa para a prática pedagógica de professores em início de carreira. O estudo se ampara em Nóvoa (1992), Garcia (1999), Romanowski (2012), entre outros. Utiliza-se como técnica de coleta de dados a entrevista semiestruturada com professores em início de carreira, em sua maioria atuante na área há aproximadamente um ano, formados no Curso de Letras - Português/Inglês da Universidade do Extremo Sul Catarinense - UNESC - e egressos do PIBID - Subprojeto Interdisciplinar. Os resultados da pesquisa mostram que o PIBID age diretamente na formação de professores e prepara os bolsistas para o início de carreira, o que aumenta sua vivência no espaço escolar e proporciona um conhecimento prévio de como é ser professor.

Palavras-chave: PIBID; Formação de professores; Professores iniciantes.

\section{ABSTRACT}

Since the mid-1990s, the Brazilian state has implemented policies that aim to regulate teacher education. One of the initiatives the federal government regarding teacher training is the Institutional Scholarship Initiative Program (PIBID). The purpose of this article is to analyze the contributions of this program to the pedagogical practice of teachers at the beginning of their careers. The study is based on Nóvoa (1992), Garcia (1999), Romanowski (2012), among others. The semi-structured interview is used as a data collection technique with early-career teachers, most of whom have been working in the area for approximately a year, graduated in the

\footnotetext{
1 Graduado em Pedagogia e Filosofia. Doutor em Educação. Docente Pesquisador do PPGE-UNESC.

2 Graduada em Letras. Professora da Rede Pública Estadual. Universidade do Extremo Sul Catarinense - UNESC.
} 
Course of Letters - Portuguese/English at the Universidade do Extremo Sul Catarinense (UNESC). PIBID Interdisciplinary Subproject. The results of the research show that the PIBID acts directly in the training of teachers and prepares the scholarship holders for the beginning of their career increasing their experience in the school space and providing a prior knowledge of what it is like to be a teacher.

Keywords: PIBID; Teacher Training; Teachers Beginners.

\title{
Introdução
}

\begin{abstract}
formação de professores é um tema de pesquisa muito discutido no campo educacional, uma vez que o professor Atem um papel crucial no que tange à qualidade do ensino. A formação não se dá apenas na universidade e acaba nela, trata-se de um processo que acompanha o desenvolvimento profissional e pessoal do professor ao longo de sua carreira.

Estudos acerca dos primeiros anos da carreira docente ainda vêm sendo pouco produzidos no âmbito da formação de professores. Um dos momentos mais críticos da docência é a passagem do sujeito da condição de acadêmico para a condição de professor. Huberman (1992) ao falar dos ciclos de vida profissional afirma que a entrada na carreira é um "choque" com a realidade da escola, um confronto entre a formação recebida e prática educativa, ou seja, o professor iniciante pode ter dificuldade de responder às necessidades da escola e de seus alunos.

Com o pensamento voltado para nessa problemática, uma dessas iniciativas foi a criação do Programa de Bolsa de Iniciação à Docência - PIBID, oferecido junto à Coordenação de Aperfeiçoamento de Pessoal de Nível Superior - CAPES. O programa insere acadêmicos de licenciatura em escolas da rede pública a fim de que aprendam, vivenciando o cotidiano escolar, o que é ser professor. Dessa forma, os acadêmicos bolsistas têm oportunidade de construir experiências de docência dentro das escolas de educação básica, futuro local de trabalho da profissão que escolheram. Além desse contato com a escola, o bolsista também conta com a supervisão de um professor coordenador na universidade e um na escola da rede pública, que vão guiá-lo tanto nas leituras e projetos como nas vivências e discussões que essa inserção na escola pública proporcionar. A partir dessas reflexões é possível intuir que os egressos desse programa tenham um início de carreira com mais segurança e tranquilidade? Assim, o presente artigo intenciona analisar as contribuições do PIBID para a prática pedagógica de professores em início de carreira.
\end{abstract}




\section{PIBID como programa de formação de professores}

Nos últimos anos, a preocupação com a formação docente tornou-se condição para o desenvolvimento de melhorias na educação que tanto urgem em nosso país. Dentre esses problemas, a desvalorização da profissão e problemas quanto à estrutura e dinâmica dos currículos dos cursos de formação de professores são os mais discutidos e os que têm mais linhas de ação em desenvolvimento. Ou seja, uma boa parte dos estudos e pesquisas desenvolvidas no campo da formação de professores elege como tema central a formação inicial. A baixa articulação entre teoria e prática conferida nos modelos dos cursos de formação inicial mostra-se como uma das principais dificuldades dos cursos destinados à formação de professores.

Para responder a essas questões o governo federal tem implementado programa que fortaleçam a formação de professores, dentre os quais, o PIBID. Esse programa é regulamentado pela Portaria no 46, de 11 de abril de 2016, que aprova o Regulamento do PIBID. Os objetivos do programa são:

I. incentivar a formação de docentes em nível superior para a educação básica; II. contribuir para a valorização do magistério; III. elevar a qualidade da formação inicial de professores nos cursos de licenciatura, promovendo a integração entre educação superior e educação básica; IV. inserir os licenciandos no cotidiano de escolas da rede pública de educação, proporcionando-lhes oportunidades de criação e participação em experiências metodológicas, tecnológicas e práticas docentes de caráter inovador e interdisciplinar que busquem a superação de problemas identificados no processo de ensino e aprendizagem; V. incentivar escolas públicas de educação básica, mobilizando seus professores como co-formadores dos futuros docentes e tornando-as protagonistas nos processos de formação inicial para o magistério; VI. contribuir para a articulação entre teoria e prática necessárias à formação dos docentes, elevando a qualidade das ações acadêmicas nos cursos de licenciatura; VII. contribuir para que os estudantes de licenciatura se insiram na cultura escolar do magistério, por meio da apropriação e da reflexão sobre instrumentos, saberes e peculiaridades do trabalho docente. VIII. articular-se com os programas de formação inicial e continuada de professores da educação básica, de forma a contribuir com a criação ou com o fortalecimento de grupos de pesquisa que potencialize a produção de conhecimento sobre ensinar e aprender na Educação Básica; 4 IX. comprometer-se com a melhoria da aprendizagem dos estudantes nas escolas onde os projetos institucionais são desenvolvidos (BRASIL, 2016, p. 3-4).

O programa oportuniza a troca de conhecimento entre os bolsistas para que haja uma valorização e aprofundamento da formação docente pretendida pelo programa. Os acadêmicos possuem um professor coordenador na 
universidade e um professor supervisor em escolas da rede pública de ensino, participantes do PIBID. Possibilita, assim, que acadêmicos bolsistas conheçam e apreendam a profissão docente no espaço escolar. Esse contato do acadêmico com um professor formado e a escola contribui para compreender a realidade que se inserirá depois de formado:

Nesse sentido, apontam que a aprendizagem da docência se desenvolve melhor quando futuros professores trabalham de perto com professores experientes e com alunos para experimentar o que eles estão aprendendo. Todo esse aprendizado é fortificado, nesse tipo de formação, pois está inserido dentro de uma comunidade de praticantes formada por professores experientes, outros alunos-professores e outros educadores; o que acaba por dar credibilidade ao programa de formação que adota essa configuração (AMBROSETTI et al., 2013, p. 156).

Além disso, o PIBID $^{1}$ oferece subsídios para que haja uma formação continuada para o professor supervisor já atuante na rede pública, o que possibilita que ele volte a estudar juntamente com os alunos bolsistas. Permite renovar, refletir e repensar a própria trajetória profissional:

É preciso entender a formação e a atividade profissional como processos articulados, superando as justaposições entre formação inicial e continuada dos professores e entre teoria e prática. Assim, a proposição de novas políticas de formação inicial baseadas na parceria entre instituições formadoras e escolas - campo do trabalho docente -, ainda que não configure uma reestruturação dos modelos de formação, pode trazer avanços no sentido de promover maior articulação entre os espaços e tempos nos percursos formativos dos professores (AMBROSETTI et al., 2013, p. 157).

Nessa tríade (professor universitário/professor rede pública/acadêmico bolsista), o programa pode contribuir para o aperfeiçoamento da educação básica e valorização da profissão, visto que, além de orientar o acadêmico que em breve estará atuando como professor, também propícia uma formação continuada para os professores já atuantes na educação básica e superior.

1 Em 2017 o PIBID passou por um processo de reformulação da proposta e de diminuição de investimentos. Parte desses investimentos foi direcionado para a criação do Programa Residência Pedagógica. 


\section{A construção da docência}

A profissão docente se constitui por um longo processo de formação que não se encerra nos cursos de formação inicial. Contudo, é importante que as instituições se comprometam com a formação de professores de modo a olhar para o seu projeto pedagógico e para o campo profissional em que se materializa a atividade docente. Ademais, as pesquisas têm apontado para a necessidade cada vez mais premente de aproximar universidade e escola como instituições que coparticipam da formação de professores. Assim, a formação de professores se constitui como um campo de pesquisa. Para Garcia (1999):

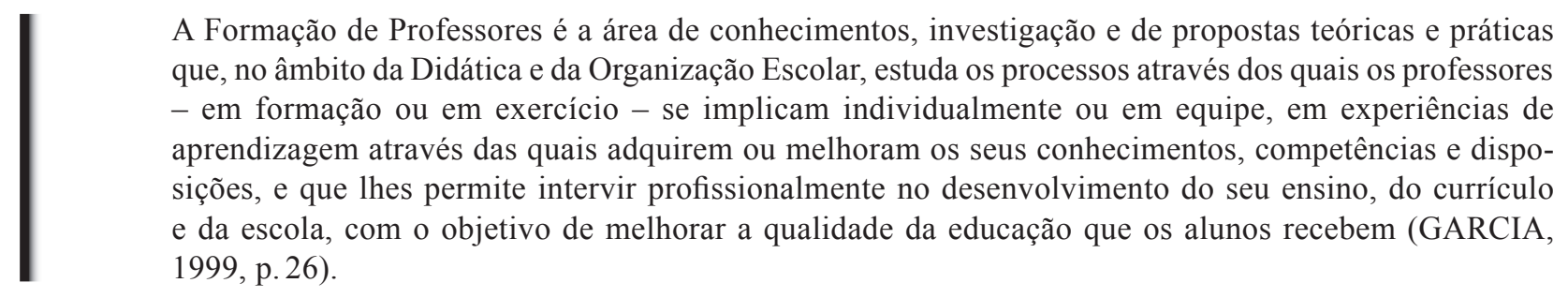

Nóvoa (1992, p. 11), ao citar Mark Ginsburg (1990), salienta que a profissão docente é influenciada por dois processos significativos: a profissionalização e a proletarização. O primeiro é o processo no qual o professor progride em sua profissão, eleva seus conhecimentos e rendimentos, passa a adquirir mais autonomia. Já o segundo processo, a proletarização, é o que vem na contramão barra essa evolução profissional. É a que também gera uma intensificação do trabalho dos professores. Muitas tarefas são atribuídas a eles ocasionando uma sobrecarga de atividades, e cria uma urgência em seguir o caminho mais simples, básico.

Garcia (1999) elege alguns princípios da formação de professores. O primeiro deles é o de considerar que essa formação é um processo contínuo que se dá por meio de um trajeto de diferentes fases, começa na formação inicial e progride no decorrer do desenvolvimento profissional. Assim, não se pode esperar que após a graduação o professor esteja "pronto", essa foi apenas a primeira etapa de um longo processo.

O segundo princípio "consiste na necessidade de integrar a formação de professores em processos de mudança, inovação e desenvolvimento curricular" (GARCIA, 1999, p. 27). Para o autor, a formação de professores deve ser considerada e incluída como estratégia na relação com o desenvolvimento curricular para, assim, facilitar a melhoria do ensino. 
Um terceiro princípio é o de "ligar os processos de formação de professores com o desenvolvimento organizacional da escola" (GARCIA, 1999, p. 28). Nessa perspectiva, o autor defende que a formação deve fazer da escola em que o professor está inserido um ambiente favorável para o aprendizado dos professores.

Em quarto lugar, o autor defende a necessidade de "articulação, integração entre a formação de professores em relação aos conteúdos propriamente acadêmicos e disciplinares, e a formação pedagógica dos professores" (GARCIA, 1999, p. 28).

O quinto princípio é o da necessidade de união entre teoria e prática, “[...] de modo a que aprender a ensinar seja realizado através de um processo em que o conhecimento prático e o conhecimento teórico possam integrar-se" (GARCIA, 1999, p.29).

O sexto princípio "é o da necessidade de procurar o isomorfismo entre a formação recebida pelo professor e o tipo de educação que posteriormente lhe será pedido que desenvolva" (GARCIA, 1999, p. 29). Dessa maneira, é necessário que haja uma coerência entre o conhecimento didático do conteúdo e o conhecimento pedagógico, levando em conta a forma como será transmitido.

Por último, "o princípio da individualização como elemento integrante de qualquer programa de formação de professores” (GARCIA, 1999, p.29). É preciso considerar o processo de formação como algo único em cada sujeito. A formação não se dará de forma igual para todos, como se houvesse uma fôrma para tal. Deve-se levar em consideração características pessoais, trajetória de vida, experiências, etc., no decorrer desse processo.

Para Nóvoa (1992), um aspecto da formação de professores que tem sido ignorado é o desenvolvimento pessoal desses sujeitos. Ao mesmo tempo em que se forma professor ele também está se formando como pessoa, os dois são indissociáveis e precisam ser considerados para que haja um melhor desenvolvimento profissional do docente. Em sua formação inicial, o professor precisa ser estimulado para uma perspectiva crítica e reflexiva, na qual seja guiado para pensamentos autônomos, tornando-o protagonista de sua própria formação.

A formação não se constrói por acumulação (de cursos, de conhecimentos ou de técnicas), mas sim através de um trabalho de reflexividade crítica sobre as práticas e de (re)construção permanente de uma identidade pessoal. Por isso é tão importante investir a pessoa e dar um estatuto ao saber da experiência (NÓVOA, 1992, p. 13).

Nóvoa, ainda, destaca a importância da coletividade no processo de formação, seja ela inicial ou continuada. A troca de experiências, aprender com o outro, ocupar os papéis de formador e formando contribuem para o fortalecimento da formação do professor. Para o autor, "O diálogo entre os professores é fundamental para 
consolidar saberes emergentes da prática profissional. Mas a criação de redes colectivas de trabalho constitui, também, um factor decisivo de socialização profissional e de afirmação de valores próprios da profissão docente." (NÓVOA, 1992, p. 14). Ao se deparar com o olhar de seus pares, os professores podem, em conjunto, trabalhar para um melhor rendimento dos seus alunos. Além de um contribuir para a formação do outro e agregar novos conhecimentos e experiências. Ganha a escola que aposta nesses momentos de troca e de reflexão em conjunto.

Para que haja a produção da profissão docente são necessárias práticas de formação que levem em conta dimensões coletivas, e que contribua para a consolidação do professor como autônomo no desenvolvimento da sua trajetória profissional (NÓVOA, 1992). Além disso, o professor precisa ser produtor de sua profissão, tendo em conta que não é ele sozinho que mudará a educação ou único responsável para o sucesso dela. Assim, pode-se considerar que a formação de professores depende de uma série de elementos que juntos formarão um profissional. A formação deve ser entendida como um exercício contínuo que se inicia nas universidades e que não acaba nelas. É na instituição de ensino a qual se inserirá, com o coletivo de professores que a formação se dará, junto ao desenvolvimento pessoal do professor.

\section{As experiências iniciais na docência}

As experiências iniciais na docência são marcadas por muitos desafios. Inicialmente, você deixa de ser um estudante de licenciatura e passa a ser um profissional em uma escola, com a sua turma e com os seus alunos. Nesse contexto, o professor iniciante se vê diante de uma realidade muito complexa e começa a perceber as aproximações e distanciamentos entre o que aprendeu nos cursos de formação de professores e o contexto escolar onde atua como docente.

De acordo com Papi e Martins (2010), nos últimos anos, os estudos acerca da formação de professores têm se ampliado em grande escala. Porém, no que tange à formação de professores principiantes, os estudos aparecem em menor número e não conseguiram ainda, apesar de reconhecida sua relevância, promover uma formação mais voltada para professores nessa condição. Nisso, ressalta-se que há uma necessidade de que o professor iniciante seja tratado diferente do professor já atuante. Além disso, as instituições de ensino superior e às de educação básica têm uma responsabilidade grande nesse processo e precisam se posicionar nessas etapas. Para as autoras não houve um entendimento desse papel, principalmente por parte das instituições de educação superior. 
[...] Essas últimas, em especial, podem se constituir como incentivadoras e fomentadoras da formação desses professores, na medida em que realizem parcerias com as escolas de educação básica e que, inclusive, não desconsiderem a formação de seus próprios professores, que, em muitos casos, são, também eles, iniciantes na profissão. (PAPI; MARTINS, 2010, s.p.).

Distinguir as diferentes etapas da carreira docente é crucial justamente pelo distinto desempenho e experiência que se mostra em cada uma dessas fases. Garcia (1999) cita em sua pesquisa Feiman (1983), que afirma que o professor passa por quatro diferentes fases em sua carreira, a saber: a primeira, chamada de pré-formação, diz respeito às experiências que o futuro professor teve enquanto era aluno, que o influenciaram mesmo que inconscientemente.

A segunda fase, denominada formação inicial, se dá dentro de instituições específicas e se trata do período de preparação formal para o exercício da profissão. É nessa fase que os futuros professores se apropriam dos conhecimentos sistematizados sobre educação, docência e prática pedagógica.

A terceira fase, de iniciação, refere-se aos primeiros anos de trabalho do professor e é a etapa mais marcante e difícil de sua trajetória. Como aponta Garcia (1999, p. 113), "É um período de tensões e aprendizagens intensivas em contextos geralmente desconhecidos, e durante o qual os professores principiantes devem adquirir conhecimento profissional além de conseguirem manter um certo equilíbrio pessoal (Borko, 1986)". Nessa etapa, passam a ocupar a posição de professores e deixam de ser estudantes.

E a última fase, formação permanente, compreende o período de atividades de formação planejadas pelo professor e pela instituição que está inserido, de forma a entender o contínuo de que se trata a formação docente. Trata-se de uma fase onde se busca ampliar o repertório de experiências para o aperfeiçoamento do trabalho pedagógico.

Embora essas fases façam parte de um todo e se relacionam, são fases específicas e que acontecem em momentos diferentes da trajetória do professor. Torna-se mais que evidente a importância e o impacto que os primeiros anos de experiência do professor têm, já que essa é a fase de mais dúvida e insegurança vivida por ele.

O início da docência é marcado por sentimentos contraditórios: de um lado a alegria e satisfação frente à possibilidade de realização da atividade profissional e da aquisição da primeira turma; do outro, o medo e a insegurança frente aos desafios postos pelo cotidiano da escola e pelo ato de educar. É o momento de colocar em prática os conhecimentos adquiridos ao longo da formação inicial, de aquisição de novas aprendizagens e de profundas mudanças. (MARTINS, 2012, p.3). 
O grande equívoco quando se trata de professores principiantes é que ele é tratado como um professor já pronto e preparado para a atuação. A escola que recebe o professor iniciante nem sempre costuma dar o suporte pedagógicos para os professores iniciantes. Já se deduz, quando ele aparece para trabalhar, que se trata de um produto finalizado, não dando a importância que essa primeira fase da carreira docente precisa. Sendo que "a iniciação é uma atividade na qual a escola enquanto unidade desempenha um papel fundamental como serviço de apoio a professores principiantes" (GARCIA, 1999, p. 113). A escola necessita assumir um papel de formador, que acolhe, auxilia e socializa esse o professor.

Outro problema encontrado na formação inicial de professores é que são poucas as oportunidades nas quais o acadêmico tem contato direto com a escola. Portanto, quando começam a atuar, os professores principiantes tiveram pouquíssimos momentos de inserção em escolas e conhecem pouco a realidade escolar pela perspectiva de docente, o que causa grande impacto e estranhamento no primeiro momento e, por vezes, gera a desistência da profissão. Ou, ainda, faz o professor caminhar por atalhos, deixando de lado a possibilidade de um trabalho mais autônomo e diferenciado.

É no período de iniciação profissional que o professor se defrontará com a realidade que está posta e com contradições que nem sempre estará apto a superar. Seus conhecimentos profissionais são colocados em xeque e a postura que assume pode ir desde uma adaptação e reprodução muitas vezes pouco crítica ao contexto escolar e à prática nele existente, a uma postura inovadora e autônoma, ciente das possibilidades, dos desafios e dos conhecimentos profissionais que sustentam sua ação pedagógica. Quando se fala sobre o período de iniciação profissional há, portanto, uma aproximação tanto de fatores pessoais quanto de fatores e aspectos profissionais, estruturais e organizacionais com os quais se defronta o professor (PAPI; MARTINS; 2010, s.p.).

A pesquisa de Romanowski (2012) indica que o sistema educacional brasileiro é composto por uma maioria de professores principiantes que, sem nenhum tipo de apoio, atuam como professores temporários e são frutos de uma formação inicial precária. Além disso, a autora ressalta que esses professores normalmente são designados a trabalhar com as turmas sobrantes, as ditas "piores" no que se refere a comportamento e rendimento escolar, já que os professores veteranos não querem. Tudo isso, ainda, sem nenhum tipo de programa específico para essa fase de iniciação à docência, pois são raros os existentes.

Com efeito, na atualidade, não há uma política de acompanhamento, apoio e formação continuada destinada aos professores principiantes nos sistemas de ensino público e privado, o que implica que poucos profissionais estão envolvidos com práticas de trabalho junto aos professores principiantes corroborando para a pouca existência de estudos sobre o tema. Tudo isto contribui para a permanência da situação de abandono com que se deparam os professores principiantes, e não favorecem a perspectiva de mudança da cultura, das políticas e práticas em torno deste período da carreira docente (ROMANOWSKI, 2012, p. 7). 
Em 1991, Garcia (1999) investigou, por meio de entrevistas, os problemas e preocupações enfrentados por 107 professores principiantes. A pesquisa concluiu que os professores principiantes se preocupam com sua trajetória e aperfeiçoamento como docente e possuem a consciência de que a formação inicial é incompleta. Constatou-se, ainda, que os primeiros anos de ensino são difíceis no âmbito pessoal e profissional; que as experiências vividas na época de estudante exercem certa influência nos professores principiantes e, por fim, os problemas mais relatados pelos professores se referem à aspectos didáticos do que a pessoais e organizacionais.

Garcia (1999, p. 115) afirma que essa fase de iniciação à docência é também um período de socialização. Seria um "processo mediante o qual os novos professores aprendem e interiorizam as normas, valores, condutas, etc..., que caracterizam a cultura escolar em que se integram". Assim, a socialização caracteriza, na iniciação à docência, o duplo movimento em que o professor adquire conhecimento e ao mesmo tempo as competências sociais necessárias para assumir um lugar na sua profissão. O autor reitera que o processo de socialização deve ser unidirecional. Ou seja, a instituição onde o professor iniciante está inserido pode colaborar nesse processo, dando o suporte para a adaptação. Sem um sentimento de pertença, de conhecimento da cultura institucional, o trabalho do professore iniciante pode ser fragilizado.

De tal modo, o processo de iniciação à docência implica em uma fase muito delicada na formação de um professor. O ideal seria que ele não estivesse sozinho, como vemos na realidade atual. Para Garcia (1999), a adaptação do professor iniciante depende, "em grande medida, das experiências biográficas anteriores, dos seus modelos de imitação anteriores, da organização burocrática em que se encontra inserido desde o primeiro momento de sua vida profissional, dos colegas e do meio em que iniciou a sua carreira docente" (GARCIA, 1999, p. 118). Somente uma iniciativa que una forças entre estado, universidades e escolas pode mudar essa realidade e assim melhor formar os professores.

\section{Metodologia, apresentação e análise de dados}

A pesquisa realizada teve como base uma abordagem qualitativa e se caracteriza como uma pesquisa descritiva, uma vez que se pretende descrever e analisar as contribuições do PIBID na prática pedagógica de professores iniciantes. Utilizou-se a entrevista semiestruturada com oito professores iniciantes egressos do PIBID - Subprojeto Interdisciplinar. A escolha pela entrevista semiestruturada se deu pela possibilidade de fazer a escuta desses sujeitos que participaram do programa como estudante de licenciatura e que, atualmente, estão na condição de professores iniciantes.

As entrevistas foram realizadas nos meses de agosto e setembro de 2017 por meio de aplicativo de celular que permite gravação de áudios. A pesquisadora enviava a pergunta via áudio e conforme o entrevistado respondia, 
também via áudio, era gravada e enviada a próxima pergunta. Todas as perguntas foram formuladas igualmente para todos os respondentes. Assim, após o recebimento das respostas realizou-se a transcrição para posterior análise.

Para a análise dos dados os entrevistados foram nomeados como P1, P2, P3, P4, P5, P6, P7 e P8 para que suas identidades fossem preservadas. A partir da leitura dos dados coletados optou-se por organizar a análise em três blocos. Sendo o primeiro sobre os sujeitos que participaram da pesquisa, o segundo sobre as experiências do PIBID na construção da docência e o último bloco sobre as experiências iniciais dos docentes no contexto escolar.

\section{Os sujeitos participantes da pesquisa}

Foram entrevistados oito professores em início de carreira formados no ano de 2016 no curso de Letras Português/Inglês da Universidade do Extremo Sul Catarinense - UNESC. Todos são egressos do PIBID - Subprojeto Interdisciplinar. O período de participação dos entrevistados no programa varia de um a três anos, sendo que cinco deles está no programa há mais de dois anos e meio. Esses cinco estão inseridos no programa pelo menos a metade do tempo de duração do curso de graduação.

Os participantes da pesquisa são todos professores contratados temporariamente, passam por diferentes escolas durante o ano, normalmente substituindo professores afastados. Todos trabalham em escolas públicas estaduais ou municipais, sendo que seis estão em escola estadual. Dois dos professores, além de atuarem em escola pública, também trabalham em escola particular. O tempo de experiência como professor dos sujeitos pesquisados é de um ano.

Assim, estão em suas primeiras experiências como professores, saíram há pouco da universidade e trabalham em escolas da rede pública de ensino. São, em totalidade, professores em caráter temporário, o que implica passar pouco tempo em uma só escola e precisar passar por muitas durante o ano. Esses professores vivenciaram boa parte do período da graduação sendo acadêmicos bolsistas do PIBID - Subprojeto Interdisciplinar e, portanto, tiveram várias experiências no cotidiano escolar antes de terminarem a licenciatura, o que nos leva a hipótese de que tenham menos dificuldade de iniciar a carreira docente do que aqueles que não participaram do programa.

\section{Sobre as experiências do PIBID na construção da docência}

A construção da docência se constitui como um processo que se estende por toda a vida profissional do sujeito. Articula, portanto, formação inicial e formação continuada. Assim, entende-se o quão é necessário pensar em um projeto de formação de professores que articule a universidade com a escola de modo que as ações formativas sejam compartilhadas. Para Ambrosetti (2013), um problema ligado à formação dos professores se refere ao distanciamento 
entre a universidade que forma o professor e as escolas de educação básica, as quais serão o ambiente de trabalho dos professores.

$\mathrm{Na}$ intenção de deixar esse distanciamento menor, o PIBID vem para estreitar o relacionamento que o acadêmico tem com a escola básica, colocando-o nas instituições de ensino de forma a conhecer melhor essa realidade e aprender com outros professores o que é ser professor.

Parece ser consenso que a formação inicial deve possibilitar um saber-fazer prático racional e fundamentado que possibilite a ação em situações complexas de ensino. Assim, o conhecimento profissional deve constituir-se a partir de vivências e análises de práticas concretas que permitam constante dialética entre a prática docente e a formação teórica e, ainda, entre a experiência concreta nas salas de aula e a pesquisa, entre professores e os formadores universitários (AMBROSETTI, 2013, p. 169).

Os oito professores em início de carreira participantes da pesquisa foram questionados sobre como os estudos, trabalhos e projetos realizados no período que participaram do PIBID contribuíram para a atuação deles como professores. Pode-se perceber que o programa agiu como agregador de conhecimento em relação à graduação. Trazendo para os participantes outros tipos de conhecimentos que na graduação, muitas vezes, pouco se explora. O que proporciona reflexões durante a prática, já que ao passo que liam teorias de como fazer, também vivenciavam a prática nas escolas.

"Bom, eu acredito que tanto os textos quanto a prática realizada no PIBID contribuíram para minha formação porque me trouxeram um conhecimento a mais, um conhecimento que agregou durante a minha formação acadêmica. E os textos eles traziam a reflexão tanto do professor, do olhar do professor, quanto da prática que a gente iria fazer nas atividades nas escolas. Então, são textos que estavam além da minha formação na minha graduação." (P1)

O PIBID garante ao estudante de licenciatura um tempo maior de vivência na escola e de observações do cotidiano, bem como o contato direto com professores já formados mais experientes. Oportuniza a compreensão da profissão docente, dos seus desafios além de momentos de reflexões acerca das ações realizadas no projeto.

"O PIBID ajudou acho que no sentido da segurança, em me deixar mais segura e mais preparada para enfrentar certas situações que a gente se depara em sala de aula, né. Porque quando a gente vai fazer o estágio ele é tenso, te deixa tensa porque tu estás sendo observada, tu sabes que está sendo avaliada. Já no PIBID não, tu tens mais um pouco de liberdade, de ir tentando, testando formas diferentes de dar aula, de projetos." (P2) 
"Na graduação tu não tem contato com a escola, o momento que tu tens contato com a escola é só no momento de avaliação. Tu tens que dar aula e tu tem que estar teoricamente já preparado para isso e o PIBID de certa forma te prepara para isso. Porque tu tens contato com a escola, tem contato com o professor, tu observas professores e tu consegues ter uma discussão sobre como tu te porta dentro de sala de aula sem ter um caráter avaliativo. Sem te preocupar com notas e essas questões." (P6)

Os professores entrevistados também mencionam a importância de ter tido um maior conhecimento do que é trabalhar interdisciplinarmente. $\mathrm{O}$ fato de todos os entrevistados serem egressos do PIBID - Subprojeto Interdisciplinar - mostra como o esclarecimento do conceito fez com que eles procurassem trabalhar, agora, com projetos coletivos em parceria com outros professores, visando práticas também interdisciplinares.

“Bom, o PIBID ele sem dúvida contribuiu muito com a minha formação. Os textos lidos eles auxiliaram muito na minha forma de pensar, de rever algumas atitudes dentro de sala de aula. Todos os projetos eles tiveram grandes contribuições, foi possivel entender o quanto é importante saber trazer a interdisciplinaridade no ambiente escolar, motivar os alunos e hoje eu percebo o quanto evolui nas minhas aulas.” (P5)

"A experiência que o PIBID me proporcionou foi de realmente saber debater, saber planejar, pensar em projeto dinâmico, um projeto que realmente vá fazer diferença na escola com os estudantes, com os professores e também assim uma mudança na sociedade. Já que o meu PIBID era interdisciplinar então eu procuro sempre trazer algo interdisciplinar para as minhas aulas e isso assim tem arrecadado bastante elogios e está sendo bem gratificante." (P7)

Nesse sentido, percebe-se que o programa teve o papel de agregar conhecimentos além do que já se estava aprendendo na graduação. Os estudos realizados, juntamente com as ações e reflexões obtidas nas reuniões e intervenções nas escolas, fizeram com que os professores se tornassem mais cooperativos, mais engajados a trabalhar em conjunto com outros professores de forma interdisciplinar, além de criar o hábito refletir sobre a prática.

Os participantes do PIBID estão semanalmente inseridos dentro das escolas com o professor supervisor. Esse fato faz com que a vivência e o conhecimento do espaço escolar sejam bem maior do que o tempo proporcionado pelos estágios na graduação, por exemplo. Questionamos os professores entrevistados se eles achavam que esse tempo a mais na escola, disponibilizado pelo programa, havia sido uma vantagem e se esse conhecimento prévio os ajudou. As respostas foram positivas já que oportunizou aos professores iniciantes maior segurança nas primeiras experiências e aliviou o choque que, normalmente, se leva ao encarar uma sala de aula de fato. 
"Sim, a experiência do PIBID me trouxe muito mais segurança no meu início de carreira docente. Porque a gente estava toda semana em sala de aula, toda semana fazendo ou colocando em prática alguma atividade né, algum planejamento. Então eu não tenho dúvidas assim do quanto essa experiência me ajudou agora para o meu início de carreira. Por questões que a gente fica mais segura, é um ambiente que o professor por ter essa experiência ele está habituado, ele está familiarizado. Então isso foi uma das grandes vantagens que o PIBID trouxe para mim." (P1)

“Com certeza! Participar do PIBID foi uma vantagem e deveria ser algo que fizesse parte da formação. Porque o estágio não nos proporciona a experiência de sala de aula que o PIBID proporciona. Porque no PIBID temos oportunidade de trocar ideias, experiências e ir tentando, testando em sala de aula." (P2)

"Sim. Porque o estágio na faculdade ele é um tempo muito curto. Tu não consegues pegar tudo que precisa para entender o contexto de uma sala de aula, de como trabalhar com os alunos. E o PIBID ele vai ao longo assim. Tu começas a estudar, depois tu vais para a sala de aula, tu começas a observar, a entender todo aquele contexto do ambiente escolar para dai partir para uma aula, para um projeto, para algo maior. Então com certeza contribuiu muito." (P5)

É possível perceber que os professores entrevistados relatam as contribuições do PIBID para a construção da docência e comparam a experiência do programa com o estágio curricular. Destacam que a experiência no PIBID colabora para amenizar o choque de realidade que os professores têm ao sair da graduação e irem para a sala de aula.

[...] temos vindo a afirmar que "os programas de iniciação têm a finalidade específica de facilitar a adaptação e integração do novo professor na cultura escolar existente. Trata-se de facilitar ao professor principiante o acesso à ecologia da escola, ou seja, as intenções, estrutura, currículo, pedagogia e sistema de avaliação que caracteriza e diferencia a escola na qual decorrerá o seu ensino (Marcelo, 1988d, p. 71)”. (GARCIA, 1999, p. 122).

Os estudos realizados nos encontros pelos participantes do programa agregam novos conhecimentos ao que eles já aprendem na graduação e fortalece a unidade teoria e prática. Ao passo que estão na graduação também realizam estudos no PIBID com a intenção de planejar e aplicar projetos de intervenção na escola com a orientação dos professores supervisores. Para Garcia (1999, p. 119), “os programas de iniciação configuram-se, como um elo imprescindível que deve unir a formação inicial ao desenvolvimento profissional ao longo da carreira docente." 
Ademais, as experiências vividas no programa mostram aos bolsistas a importância de se construir um planejamento que leve em consideração as necessidades do aluno e que após a sua aplicação se possa refletir de modo compartilhado sobre os resultados obtidos com o intuito de avaliar o que funcionou e o que pode melhorar. É nesse horizonte que se constitui uma docência reflexiva e autônoma. Não se trata, aqui, de supervalorizar o programa diante de tantas outras iniciativas de formação de professores, busca-se, portanto, analisar a sua potencialidade com vista a qualificação da docência.

\section{As experiências iniciais dos docentes no contexto escolar}

Procurou-se investigar neste estudo como foram as primeiras experiências dos entrevistados como professores, quais foram os desafios encontrados e de que forma eles buscaram enfrentar esses problemas. Nos relatos emergem várias dificuldades como a estrutura escolar e o comportamento dos alunos. Enfatizam também a insegurança na seleção de conteúdos para trabalhar em cada turma.

Foi possível perceber nas respostas que os professores não relatam dificuldades relacionadas ao choque de realidade ao se depararem com uma turma só deles. Eles já sabiam o que os esperava e estavam mais seguros para enfrentarem tal desafio. Isso pode ser atribuído ao fato de terem participado do PIBID e assim já conhecerem mais essa realidade.

Os professores responderam também como foi a chegada às instituições de ensino em que trabalham, se de alguma forma elas os apoiaram, orientaram ou tiveram uma atenção especial por serem professores em início de carreira. O professor iniciante começa sem nenhum tipo de apoio e a instituição de ensino não se vê como formadora daquele professor, não há um acolhimento, a escolar o encara como um produto acabado. Os relatos demonstram essa falta de orientação, principalmente em escolas estaduais. Percebemos que eles até são bem recebidos pelos professores em geral. Mas que são encarados pelos colegas e equipe diretiva como alguém pronto, que não necessita de uma maior atenção.

"No estado o professor está sozinho, ele não tem um suporte, não tem com quem trocar ideias, não tem com quem conversar, não tem com quem trocar experiências. É simplesmente chegar, dar aula e sair. É um mundo bastante solitário. Em questão de experiência assim, não se tem essa troca. Agora, no município, já é um pouquinho diferente." (P1)

"Simplesmente me mostraram a sala que eu deveria ir, algumas me entregaram o material deixado pelo professor anterior e deu. Literalmente, "se vira!'. Essas experiências foram nas escolas estaduais. Porém, 
quando eu me deparei com uma escola do município, tudo mudou. A diretora me acolheu, sentou comigo, explicou tudo, me apresentou a escola e todos." (P2)

"Nos primeiros meses que eu trabalhei na escola que eu comecei a lecionar, ao mesmo tempo em que eu fui bem recepcionada pelos professores, pela diretora, por ser ex-aluna, houve o problema de não ter nenhuma discussão sobre como trabalhar. Não tinha nenhum suporte pedagógico, ninguém olhando os planos de aula, algum tipo de orientação. E por mais que os professores fossem abertos para tirar dúvidas, nem sempre era possivel. Às vezes, eles criavam uma espécie de barreira entre os professores de determinada disciplina, alguns professores acabavam se fechando, então, era bem difícil. Por isso, a adaptação acaba sendo mais difícil, porque tu te sentes tão perdida e tu não sabe com quem conversar, sobre o que conversar, porque eles, as pessoas entendem que por ter saído recentemente da faculdade tu já tem o conhecimento necessário para poder lecionar." (P6)

Ao iniciarem a carreira, os professores, na maioria das vezes, têm pouco ou nenhum apoio da escola que se inserem. Resta a eles se apegarem aos ensinamentos obtidos na graduação e procurar referências (professores mais experientes, por exemplo) para os auxiliarem no início de carreira. Percebemos que ao se depararem com esse abandono, os entrevistados recorreram às suas experiências no PIBID e buscam no professor supervisor, no coordenador de área e nos estudos realizados o apoio para enfrentarem os desafios da melhor forma.

\section{Considerações finais}

A partir da análise resultante das entrevistas feitas com os professores em início de carreira, egressos do PIBID Subprojeto Interdisciplinar, percebemos que o programa se mostrou um importante parceiro do período da graduação, pois trouxe novos conhecimentos, novos olhares, proporcionou rica troca de experiências e o mais importante, estreitou a relação teoria-prática ao inserir os bolsistas nas escolas públicas. O contato prévio com a sala de aula preparou os professores e amenizou o choque de realidade característico do período inicial da carreira docente.

O programa proporcionou o contato direto com professores mais experientes. Percebemos que os professores supervisores exercem o papel de guia nos momentos que os bolsistas precisaram atuar e essa troca de experiência foi uma forma de "ensaiar" o que eles fariam quando saíssem da graduação.

Além disso, o exercício de planejar e refletir as ações que seriam executadas no projeto criou nos participantes da pesquisa o hábito de observar a sala de aula, verificar o que é pertinente trabalhar e assim criar um projeto relevante para sua disciplina, mas também interdisciplinar. Os projetos realizados pelo PIBID nas escolas mostraram aos 
professores a importância de criar parcerias dentro da escola com outros professores e também a importância de refletir acerca do seu planejamento e da sua trajetória como profissional da educação.

Apesar de passarem por todas as dificuldades que professores em início de carreira passam, concluímos que aqueles que participam do PIBID se sentem mais seguros, conhecem melhor o cotidiano escolar e estão mais aptos a trabalhar em conjunto. O programa contribuiu para diminuiu o choque que, normalmente, existe ao se deparar com o início da carreira docente. Possibilita aos bolsistas a troca de experiências, reflexões acerca do ser professor e contribuiu para que os professores iniciantes se sintam mais preparados e capazes para os desafios encontrados na sala de aula.

Percebemos que o programa cumpre o papel de melhorar à educação básica e melhor qualificar os professores. Deparamo-nos com profissionais diferentes por terem participado do programa, profissionais mais autônomos e seguros, que sabem pensar e agir de forma coletiva e que apesar do pouco apoio buscam a excelência no que fazem. Assim, além de reduzir as dificuldades dessa transição de aluno para professor, o PIBID se mostra como importante programa para que o professor crie sua identidade profissional.

\section{Referências}

AMBROSETTI, Neusa Banhara et al. Contribuição do PIBID para a formação inicial de professores: o olhar dos estudantes. Educação em Perspectiva, Viçosa, v. 4, n. 1, p. 151-174, jan./jun. 2013. Disponível em: <http://www.seer.ufv.br/seer/educacaoemperspectiva/ index.php/ppgeufv/article/view/405/106>. Acesso em: 18 abr. 2016.

BRASIL. Coordenação de Aperfeiçoamento Pessoal de Nível Superior. Pibid Programa de Bolsa de Iniciação à Docência. Portaria $\mathrm{n}^{\mathrm{o}}$ 46, de 11 de abril de 2016. Disponível em: <https:/www.capes.gov.br/images/stories/download/legislacao/15042016-Portaria-46Regulamento-PIBID-completa.pdf>. Acesso em: 18 abr. 2016.

BRASIL. Decreto no 7.219, de 24 de junho de 2010. Dispõe sobre o Programa Institucional de Bolsa de Iniciação à Docência - PIBID e dá outras providências. Diário Oficial da União, Brasília: Casa Civil da Presidência da República, 2010. Disponivel em: <http:// www.planalto.gov.br/ccivil_03/_ato2007-2010/2010/decreto/d7219.htm>. Acesso em: 18 abr. 2016.

BRASIL. Projeto de Lei n. 227. Residência Pedagógica. Senado Federal. Brasília, 2007. Disponível em: <http://www.capes.gov.br/ educacao-basica/programa-residencia-pedagogica>. Acesso em: 18 abr. 2016

FUNDAÇÃO CARLOS CHAGAS (Org.). Um estudo avaliativo do Programa Institucional de Bolsas de Iniciação à Docência (Pibid). São Paulo: Fundação Carlos Chagas, 2014. Disponível em: <https://www.capes.gov.br/images/stories/download/bolsas/24112014-pibidarquivoAnexado.pdf>. Acesso em: 18 abr. 2016.

GARCIA, Carlos Marcelo. Formação de professores para uma mudança educativa. Portugal: Editora Porto. 1999.

GERHARDT, Tatiana Engel; SILVEIRA, Denise Tolfo (Org.). Métodos de Pesquisa. 2009. Disponível em: <http://www.ufrgs.br/ cursopgdr/downloadsSerie/derad005.pdf>. Acesso em: 15 set. 2017. 
HUBERMAN Michaël. O ciclo de vida profissional dos professores. In: NÓVOA, António. Vida de professores. Porto: Editora Porto, 1992.

MARCONI, Marina de Andrade; LAKATOS, Eva Maria. Fundamentos de metodologia científica. 7. ed. São Paulo: Atlas, 2010. 297 p.

MARTINS, Francine de Paulo. Professores iniciantes: desafios da profissão docente. Anais do III Congresso Internacional sobre Profesorado Principiante e inserción Profesional a la Docencia. Santiago do Chile. 2012. Disponível em: <http://congressoprinc. com.br/artigo?id_artigo=283> Acesso em: 10 set. 2017.

NÓVOA, António. Formação de Professores e profissão docente. In: NÓVOA, António (Org.). Os professores e a sua formação. Lisboa: Dom Quixote, 1992.

PAPI, Silmara de Oliveira Gomes; MARTINS, Pura Lúcia Oliver. As pesquisas sobre professores iniciantes: algumas aproximações. Educação em Revista, Belo Horizonte, 2010.

PARRA FILHO, Domingos; SANTOS, João Almeida. Metodologia Científica. Belo Horizonte: Cengage Learning, 2011.

ROMANOWSKI, Joana Paulin. Professores principiantes no Brasil: questões atuais. Anais do III Congresso Internacional sobre Profesorado Principiante e inserción Profesional a la Docencia. Santiago do Chile. 2012. Disponível em: <http://congressoprinc. com.br/artigo?id_artigo=195> Acesso em: 10 set. 2017.

Recebido em: maio/2018

Aceito em: outubro/2018

Endereço para correspondência:

Ricardo Luiz de Bittencourt <rlb@unesc.net>

Av. Universitária, 1105 - Universitário

88806-000, Criciúma, SC, Brasil 